\title{
Qualidade de Vida no Trabalho: Um Estudo de Caso em uma Distribuidora de Cosméticos Situada em Paulista/PE
}

\author{
Quality of Work Life: A Case Study at Cosmetics Distributor Located in Paulista/PE
}

Nicolas Mattos Trindade ${ }^{1}$ (D) https://orcid.org/0000-0001-7036-4342

Ana de Fátima Braga Barbosa1 (D) https://orcid.org/0000-0001-9747-4939

${ }^{1}$ Pós-graduação em Gestão da Qualidade e Produtividade, Escola Politécnica de Pernambuco-UPE, Pernambuco, Brasil.

E-mail do autor principal: Nicolas Mattos Trindade nicolas.mtrindade@gmail.com

\section{RESUMO}

O presente artigo teve como objetivo geral avaliara percepção que os colaboradores de uma microempresa, distribuidora de cosméticos, têm sobre a sua qualidade de vida no trabalho. Para análise da percepção, foi realizada uma pesquisa de campo de caráter descritivo, que buscou verificar o nível de satisfação de qualidade de vida no trabalho dos colaboradores da microempresa, de acordo com os 8 fatores do modelo de Walton. Além disso, houve questões referentes a dados sociodemográficos. Como resultado, foram obtidos 3 fatores críticos classificados em um nível de satisfação razoável, sendo justificados através da relação com os dados sociodemográficos. Os demais fatores foram classificados entre os níveis de satisfação bom e ótimo. De um modo geral, a distribuidora não apresentou níveis de satisfação classificados como ruins e péssimos, apenas os níveis razoável, bom e ótimo.

PALAVRAS-CHAVE: Qualidade de vida no trabalho; Modelo de Walton; Distribuidora de cosméticos; Microempresa.

\section{ABSTRACT}

The objective of this article was to evaluate the perception that the employees of a small company, a cosmetics distributor, have on their quality of work life. To analyze the perception, a descriptive field research was carried out, which sought to verify the level of satisfaction of quality of work life of employees in asmall company, according to the 8 factors of the Walton model. In addition, there were questions regarding sociodemographic data. As a result, 3 critical factors were observed and classified into a level of reasonable satisfaction, and justified by the relationship with sociodemographic data. The other factors were classified as good and optimal satisfaction levels. In general, the distributor did not show any levels of satisfaction rated as bad or worst, only reasonable, good and great levels.

KEY-WORDS: Quality of work life; Walton's Model; Cosmetics Distributor; Small Company. 


\section{INTRODUÇÃO}

No século XXI as empresas buscam uma maior competitividade em um mundo cada vez mais globalizado e com isso, as organizações enxergam que quanto mais qualidade de vida no trabalho, maiores são os retornos sobre a produtividade, tornando-se competitivas, proporcionando uma maior participação, integração e desenvolvimento do trabalhador.

No Brasil e no mundo, organizações têm reconhecido a importância do seu capital humano, sendo comum, grandes e médias empresas, assim como, órgãos público apresentar programas de qualidade de vida no trabalho (PQVT). No entanto, às micro e pequenas empresas apresentam pouca preocupação com seu capital humano.

Segundo o serviço de apoio as micro e pequenas empresas (SEBRAE), no Brasil os pequenos negócios representam cerca de 98,5\% das empresas do país, sendo responsáveis por $27 \%$ do produto interno bruto (PIB) brasileiro. Além disso, respondem por $53,4 \%$ do PIB no setor de comércio. Existe uma estimativa que até o ano de 2022, o número de micro e pequenas empresas chegue a ser $43 \%$ maior do que o número atual, ou seja, cerca de 17,7 milhões de pequenos negócios [1].

Apesar de representar um papel importante na economia brasileira, apresentando um saldo de acumulo de 327 mil novos postos de trabalho nos sete primeiros meses de 2017, há pouca preocupação com os trabalhadores que ocuparão essas novas vagas de trabalho.

Sabendo que o fator humano é o que diferencia a qualidade do serviço e, segundo Lascio [2], nenhuma empresa pode oferecer produtos ou serviços sem que os seus colaboradores apresentem um bom nível de qualidade de vida, o presente artigo tem como objetivo geral avaliar a percepção que os colaboradores de uma microempresa, distribuidora de cosméticos, têm sobre a sua qualidade de vida no trabalho. Para isso, é preciso identificar os fatores que possam interferir na qualidade de vida no trabalho (QVT), o nível de satisfação e a importância que os colaboradores dão aos fatores que influenciam a QVT, e levantar as características sociodemográficas dos colaboradores.

\section{ORIGENS E EVOLUÇÃO HISTÓRICA DA QUALIDADE DE VIDA NO TRABALHO (QVT)}

A preocupação com o trabalhador começa a ser estudada após o surgimento da teoria das relações humanas em 1930 nos Estados Unidos, sendo uma consequência de uma pesquisa desenvolvida por Elton Mayo. A nova teoria surgiu como um movimento que se opôs à teoria clássica da administração que tinha como conceitos a autoridade, hierarquia, racionalização do trabalho, departamentalização e princípios gerais da administração. Com a pesquisa de Mayo colocando em "cheque" os conceitos clássicos, surgem novos conceitosbaseados no aspecto do homem social [3].

Em 1950, o termo qualidade de vida no trabalho foi utilizado por Eric Trist e seus colaboradores no Tavistock Institute, mostrando experiências calcadas no vínculo indivíduotrabalho-organização, tendo como base a análise e reestruturação da tarefa, com o intuito de facilitar o trabalho e aumento da produtividade. Nos Estados Unidos durante a década de 60, foram criados aNational Comission on Produtivity e o congresso National Center for Produtivity and Quality of Working Life trazendo um maior incremento na preocupação com a QVT através de análises e estudos da baixa produtividade em indústrias americanas [4].

A maior participação do Japão no mercado internacional durante a década de 1970, e a difusão de técnicas administrativas japonesas, despertou nas organizações ocidentais um olhar diferente, gerando questionamentos a respeitos das práticas de gestão utilizadas no ocidente [5]. Além disso, em 1973, Walton publicou um importante estudo que propõe o equilíbrio entre trabalho e vida, tendo como destaque o papel social da organização e a importância de conjugar produtividade com os programas de qualidade no trabalho (PQVT). No final dessa década, surgiram os trabalhos de Westly e Hackman e Holdham, com a sugestão de levar a qualidade de processos e produtos para a qualidade de vida das pessoas [6].

No Brasil, tem o estudo de Limogi-França que apresenta o ponto de vista atrelado a três escolas, sendo elas: escola organizacional, escola socioeconômica e a escola da condição humana no trabalho [7]. 


\subsection{Conceitos de Qualidade de Vida no Trabalho}

Conceituar qualidade de vida no trabalho é algo difícil, visto que, as percepções de QVT variam em como o autor relaciona homem e trabalho. Para Hackman e Lawler apud Gonçalves, qualidade de vida no trabalho está relacionada com a conquista de satisfação pessoal do colaborador, ou seja, a definição é centrada na percepção do indivíduo. Sendo assim, a variedade de sentimento no trabalho que 0 indivíduo experimenta gera o grau de satisfação [8].

Para Toledo apud Andrade:

[...] princípios e movimentos na área do comportamento organizacional no trabalho foram amplamente propagados, tendo todos como preocupação central a operacionalização de condições que permitissem uma melhor qualidade de vida no trabalho [9].

Walton apresenta uma preocupação com os valores humanísticos e ambientais da organização, sendo assim, a QVT tem como meta:

[...] gerar uma organização mais humanizada, na qual o trabalho envolve, simultaneamente, relativo grau de responsabilidade e de autonomia ao nível do cargo, recebimento de recursos de feedback sobre o desempenho, com tarefas adequadas, variedade, enriquecimento do trabalho e com ênfase no desenvolvimento pessoal do indivíduo [10].

Limogi-França define QVT como:

Conjunto das ações de uma empresa que envolve a implantação de melhorias e inovações gerenciais e tecnológicas no ambiente de trabalho. A construção da QVT ocorre a partir do momento em que se olha a empresa e as pessoas como um todo, o que chamamos de enfoque biopsicossocial. 0 posicionamento biopsicossocial representa 0 fator diferencial para a realização de diagnóstico, campanhas, criação de serviços e implantação de projetos voltados para a preservação e desenvolvimento das pessoas, durante o trabalho na empresa [11].

\subsection{Modelos de QVT}

Levando em consideração que vários autores desenvolveram metodologias de pesquisa em qualidade de vida no trabalho, neste estudo foram destacados os principais: Hackman e Oldham, Westley, Werther e Davis, Nadler e Lawler, e Walton.

\subsubsection{MODELO DE HACKMAN E OLDHAM}

O modelo de Hackman e Oldham propõe que os resultados pessoais e do trabalho estão relacionados com três estados psicológicos críticos. Já os estados psicológicos críticos são criados pela presença de cinco dimensões básicas do trabalho, sendo elas: Variedade de habilidades, identidade da tarefa, significado da tarefa, autonomia e feedback [7]. A Figura 1 representa este modelo.

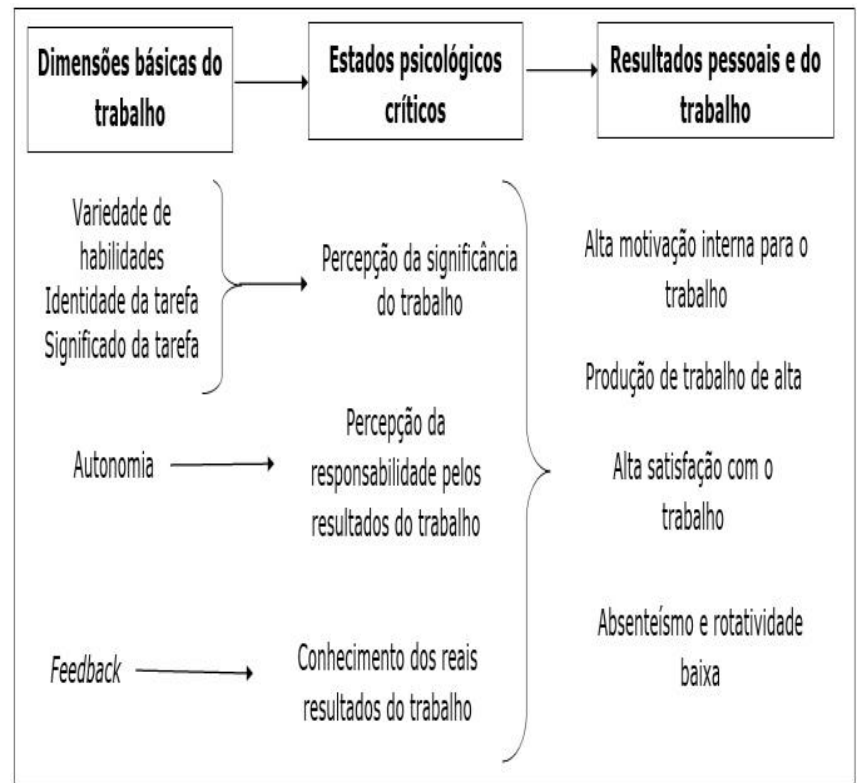

Figura 1: Representação do modelo Hackman e Oldham Fonte: [7].

\subsubsection{Modelo de Westley}

Westley em seu estudo enumerou quatro categorias de problemas que interferem no trabalho do indivíduo, além disso, identificou as causas e consequências de cada problema e indicou as possíveis soluções para eliminação. As quatro categorias são classificadas em: injustiça, insegurança, isolamento e anomia [7]. O Quadro 
1 ilustra as categorias, causa e consequência e as soluções sugeridas, segundo Westley.

Quadro 1: Fatores que influenciam a qualidade de vida no trabalho - Modelo Westley.

\begin{tabular}{|c|c|c|c|c|}
\hline $\begin{array}{c}\text { Natureza } \\
\text { do problema }\end{array}$ & $\begin{array}{c}\text { Sintoma do } \\
\text { problema }\end{array}$ & $\begin{array}{l}\text { Açäo para } \\
\text { solucionar } 0 \\
\text { problema }\end{array}$ & Indicadores & Propostas \\
\hline $\begin{array}{c}\text { Fatores } \\
\text { Económicos } \\
(1850)\end{array}$ & Injustiça & $\begin{array}{l}\text { Uniäo dos } \\
\text { trabalhadores }\end{array}$ & $\begin{array}{l}\text { - Insatisfacãa } \\
\text { - Grevese } \\
\text { sabotagem }\end{array}$ & $\begin{array}{l}\text { - Cooperação } \\
\text { - Divisão dos lucros } \\
\text { - Participação nas decisões }\end{array}$ \\
\hline $\begin{array}{c}\text { Fatores } \\
\text { Políticos } \\
(1850-1950)\end{array}$ & Insegurança & Posiç̧es Politicas & $\begin{array}{l}\text { - Insatisfacãão } \\
\text { - Greves e } \\
\text { sabotagem }\end{array}$ & $\begin{array}{l}\text { - Trabalho auto-supervisionado } \\
\text { - Conselho de trabalhadores } \\
\text { - Participacăăo nas decisóes }\end{array}$ \\
\hline $\begin{array}{c}\text { Fatores } \\
\text { Psicológicos } \\
(1950)\end{array}$ & Isolamento & $\begin{array}{l}\text { Agentes de } \\
\text { mudança }\end{array}$ & $\begin{array}{l}\text { - Sensação de } \\
\text { isolamento } \\
\text { - Absenteismo } \\
\text { e turnover }\end{array}$ & - Valorização das tarefas \\
\hline $\begin{array}{c}\text { Fatores } \\
\text { Sociológicos }\end{array}$ & Anomia & $\begin{array}{l}\text { Grupos de auto- } \\
\text { desenvolvimento }\end{array}$ & $\begin{array}{l}\text { - Desinteresse } \\
\text { pelo trabalho } \\
\text { - Absenteismo } \\
\text { e turnover }\end{array}$ & $\begin{array}{l}\text { - Métodos sócios-tecnicamente } \\
\text { aplicados aos grupos de trabalho: } \\
\text { valorização das relaçöes inter- } \\
\text { pessoais, distribuiçăor de } \\
\text { responsabilidade na equipe, etc). }\end{array}$ \\
\hline
\end{tabular}

Fonte: [7].

- Fatores econômicos - São relacionados a igualdade salarial, condições e ambiente de trabalho, carga horária;

- Fatores políticos - São relacionados a liberdade de expressão, atuação do sindicato, segurança no emprego, valorização do cargo e relacionamento com alta gerência;

- Fatores psicológicos - São relacionados ao nível de desafio, desenvolvimento pessoal, diversidade e identificação de tarefas, realização do potencial;

- Fatores sociológicos - São relacionados à valorização pessoal, relacionamento entre os funcionários, participação de decisões.

\subsubsection{MODELO DE WERTHER E DAVIS}

O modelo de Werther e Davis tem como base a exploração de cargos, levando em consideração os fatores ambientais, organizacionais e comportamentais, conforme o Quadro 2.
Quadro 2: Fatores que influenciam a qualidade de vida no trabalho - Modelo Werther e Davis.

\begin{tabular}{|c|c|c|}
\hline Elementos Organizacionais & Elementos Ambientais & $\begin{array}{c}\text { Elementos } \\
\text { Comportamentais }\end{array}$ \\
\hline $\begin{array}{l}\text { - Abordagem mecanicista } \\
\text { - Fluxo de trabalho } \\
\text { - Práticas de trabalho }\end{array}$ & $\begin{array}{l}\text { - Habilidadese } \\
\text { disponibililidades de } \\
\text { empregados } \\
\text { - Expectativas sociais }\end{array}$ & $\begin{array}{l}\text { - Autonomia } \\
\text { - Variedade } \\
\text { - Identidade de tarefla } \\
\text { - Retroinformação }\end{array}$ \\
\hline
\end{tabular}

Fonte:[7].

Os elementos organizacionais abordam a projeção de cargos mais eficientes, resultando em uma maior produtividade, através do aumento da motivação dos trabalhadores [12]. Para isso faz o uso de três aspectos: a abordagem mecanicista, fluxo de trabalho e práticas de trabalho. A abordagem mecanicista tem 0 objetivo de minimizar o tempo e o esforço dispensado pelos trabalhadores tratando cada cargo de forma detalhada. O fluxo de trabalho está relacionado à natureza do serviço ou produto e práticas de trabalho, a forma como as tarefas são executadas [8].

Os elementos ambientais são considerados nas expectativas sociais com relação ao cargo ou tarefa, assim como as habilidades e disponibilidade dos colaboradores, sendo imprescindíveis para um alto grau de motivação e satisfação [12].

Os elementos comportamentais são considerados nos aspectos da relação entre o colaborador e a tarefa a ser executada, sendo elementos fundamentais para proporcionar um aumento no sentimento de reconhecimento, autoestima e responsabilidade $[\mathbf{8} ; \mathbf{1 2}]$.

\subsubsection{MODELO DE NADLER E LAWLER}

O modelo proposto por Nadler e Lawler defende a participação dos colaboradores na tomada de decisões, autonomia e reestruturação do trabalho, sistema de recompensas e melhoria das condições de trabalho [13]. Além dessas atividades, descreveram seis princípios para o sucesso da QVT [9]:

- Percepção da necessidade;

- Foco do problema que é destacado na organização; 
- Estrutura para identificação e solução do problema;

- Compensações projetadas tanto para os processos quanto para os resultados;

- Sistemas múltiplos afetados;

- Envolvimento amplo da organização.

\subsubsection{MODELO DE WALTON}

De acordo com Junior [12] apud Walton, em decorrência dos avanços tecnológicos, da produtividade e do crescimento econômico, a expressão "qualidade de vida no trabalho" tem sido usada como uma forma de resgatar conceitos humanísticos e ambientais que estão sendo ignorados.

Para Walton, a dificuldade em identificar e segregar todos os fatores que influencia a QVT, diz o quanto é complexo a redução da insatisfação dos colaboradores. Tendo isso em vista, o seu modelo apresenta ser o mais amplo, visto que, além de apresentar fatores ligados diretamente ao cargo, acrescenta variáveis que dependem somente da organização, sendo ambos valorizados pelo colaborador [13].

Sendo assim, o modelo apresenta oito indicadores que influenciam o trabalhador, sendo eles: compensação justa e adequada, condições de segurança e saúde no trabalho, utilização e desenvolvimento de capacidades, oportunidades de crescimento contínuo e segurança, integração social na organização, constitucionalismo, trabalho e espaço total de vida, relevância social da vida no trabalho, de acordo com o Quadro 3 [12].

Quadro 3: Fatores do Modelo de Walton (continua).

\begin{tabular}{|c|c|}
\hline FATORES & DIMENSÕES \\
\hline $\begin{array}{c}\text { Compensação justa e } \\
\text { adequada }\end{array}$ & $\begin{array}{l}\text { Equidade interna e externa, } \\
\text { Justiça na compensação, } \\
\text { Partilha nos ganhos de } \\
\text { produtividade, } \\
\text { Proporcionalidade entre os } \\
\text { salários. }\end{array}$ \\
\hline Condições de trabalho & $\begin{array}{l}\text { Jornada de trabalho razoável, } \\
\text { Ambiente físico seguro e } \\
\text { saudável, Ausência de } \\
\text { insalubridade. }\end{array}$ \\
\hline
\end{tabular}

Quadro 3: Fatores do Modelo de Walton (continua).

\begin{tabular}{|c|c|}
\hline FATORES & DIMENSÕES \\
\hline $\begin{array}{c}\text { Uso e } \\
\text { desenvolvimento de } \\
\text { capacidades }\end{array}$ & $\begin{array}{l}\text { Autonomia, Habilidades } \\
\text { múltiplas, Informação sobre o } \\
\text { processo de trabalho, } \\
\text { Autocontrole relativo }\end{array}$ \\
\hline $\begin{array}{l}\text { Oportunidade de } \\
\text { crescimento e } \\
\text { segurança }\end{array}$ & $\begin{array}{l}\text { Possibilidade de carreira, } \\
\text { Crescimento pessoal, } \\
\text { Perspectiva de avanço salarial, } \\
\text { Segurança no emprego. }\end{array}$ \\
\hline $\begin{array}{c}\text { Integração social na } \\
\text { organização }\end{array}$ & $\begin{array}{l}\text { Ausência de preconceitos, } \\
\text { Igualdade, } \\
\text { Mobilidade, } \\
\text { Relacionamento, } \\
\text { Senso comunitário. }\end{array}$ \\
\hline Constitucionalismo & $\begin{array}{l}\text { Privacidade pessoal, } \\
\text { Liberdade de expressão, } \\
\text { Tratamento imparcial, } \\
\text { Direitos de proteção ao } \\
\text { trabalhador, } \\
\text { Direitos trabalhistas. }\end{array}$ \\
\hline $\begin{array}{l}\text { Trabalho e o espaço } \\
\text { total de vida }\end{array}$ & $\begin{array}{l}\text { Estabilidade de horários, } \\
\text { Poucas mudanças geográficas, } \\
\text { Tempo para lazer e família, } \\
\text { Papel balanceado no trabalho. }\end{array}$ \\
\hline $\begin{array}{l}\text { Relevância social da } \\
\text { vida no trabalho }\end{array}$ & $\begin{array}{l}\text { Imagem da empresa, } \\
\text { Responsabilidade social da } \\
\text { empresa, } \\
\text { Responsabilidade social dos } \\
\text { produtos, } \\
\text { Práticas de emprego. }\end{array}$ \\
\hline
\end{tabular}

Fonte: [13].

\section{METODOLOGIA}

\subsection{Ferramenta de Coleta de Dados}

Para a coleta de dados foi utilizado um questionário, desenvolvido por um grupo de estudantes da Universidade Federal de Pernambuco, do Centro Acadêmico do Agreste (CAA), sob a orientação do professor e mestre Luiz Sebastião. O questionário, anexo 1, foi composto por 35questões baseadas nos 8 fatores de Walton, além disso, houve 6 questões referente a dados sociodemográficos.

A pesquisa foi aplicada nos dias 20/03/2018 e 02/04/2018, sendo realizada no auditório da 
distribuidora de cosméticos, localizada na cidade de Paulista-PE. A empresa funciona nos turnos da manhã e tardecom o total de 46 colaboradores, distribuídos entre os setores administrativo e de venda, com faixa etária entre menor de 20 anos a maior de 50 anos.

\subsection{Análise dos Dados}

Com os dados obtidos do questionário, foram identificados os fatores críticos através de uma média aritmética, onde os valores respondidos foram somados e divididos pela quantidade de funcionários. Como a medida do grau de satisfação foi obtida de forma quantitativa, foiusada uma tabela para transforma esse resultado em qualidade, conforme a Tabela 1.

Tabela 1: Níveis de QVT de acordo com a média de satisfação.

\begin{tabular}{|cc|}
\hline NíVEL DE QVT & MÉdIA DE SATISFAÇÃO \\
\hline Péssima & 0 até 1,0 \\
\hline Ruim & 1,1 até 2,0 \\
\hline Razoável & 2,1 até 3,0 \\
\hline Boa & 3,1 até 4,0 \\
\hline Ótima & 4,1 até 5,0 \\
\hline
\end{tabular}

Fonte: [8].

\section{RESULTADOS E DISCUSSÕES}

\subsection{Características sociodemográficas dos colaboradores}

Foram entrevistados 46 colaboradores, sendo 38 do gênero feminino correspondente a $83 \%$ e 8 do gênero masculino correspondente a $17 \%$, conforme o Gráfico 1.

Gráfico 1: Análise de Gênero.

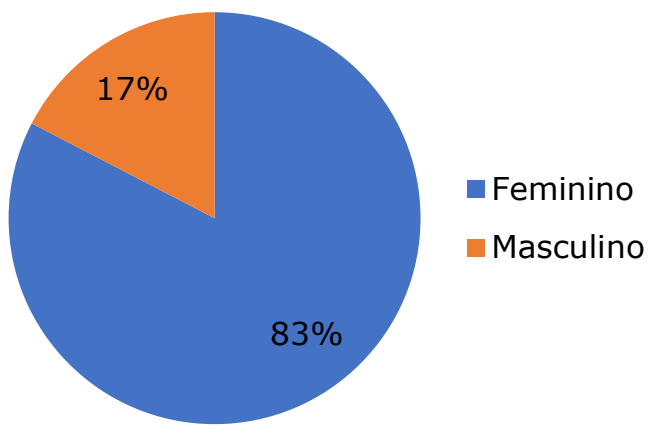

Fonte: Autor.
O Gráfico 2, apresenta a faixa etária dos colaboradores da distribuidora, sendo possível a análise de que grande parcela dos entrevistados possui faixa etária entre $31-40$ anos correspondendo a $41 \%$, seguido da faixa etária entre 46-50 anos correspondendo a $18 \%$, ou seja, apenas $19 \%$ dos colaboradores possuem faixa etária até 30 anos.

Gráfico 2:Análise de Faixa Etária.

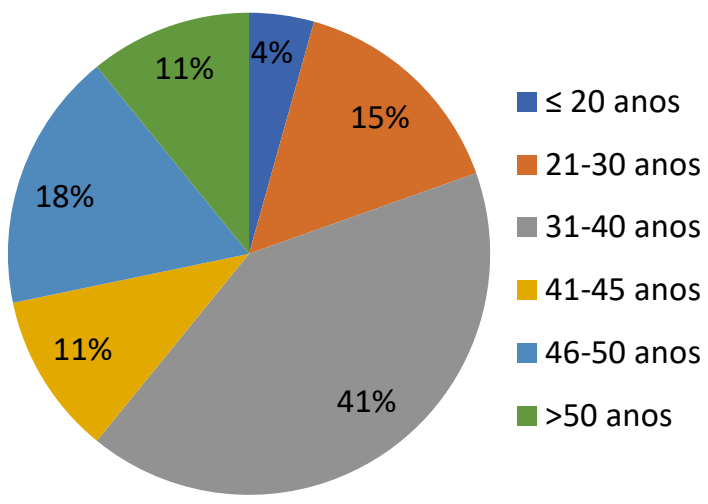

Fonte: Autor.

Em relação ao nível de escolaridade, os colaboradores possuem cinco níveis: ensino médio, técnico, superior incompleto, superior completo e pós-graduação, conforme o Gráfico 3.

Gráfico 3: Nível de Escolaridade

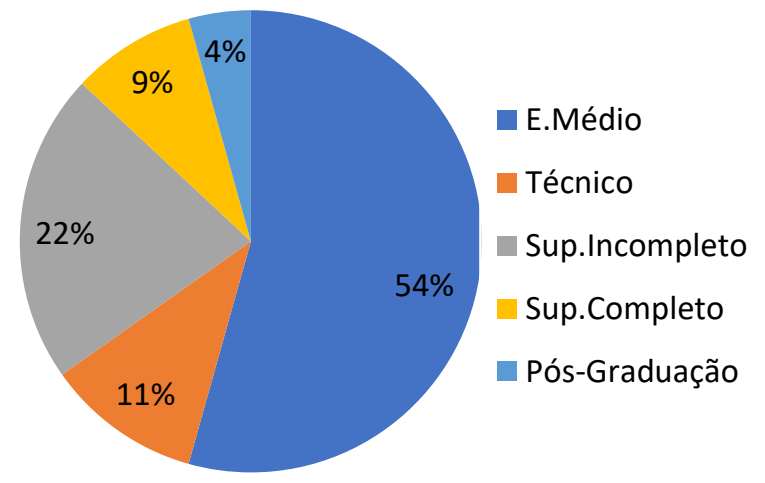

Fonte: Autor.

Quanto ao setor de trabalho, o Gráfico 4 apresenta que $80 \%$ dos colaboradores atuam na área de vendas e $20 \%$ atuam na área administrativa. Ao relacionar o Gráfico $4 \mathrm{com}$ o Gráfico 1 , foi possível perceber que dos $83 \%$ das mulheres, $76 \%$ atuam no setor de vendas e $7 \%$ na área administrativa. Já, o gênero masculino 
dos $17 \%, 4 \%$ atuam no setor de vendas e $13 \%$ na área administrativa.

Gráfico 4:Análise de Setor.

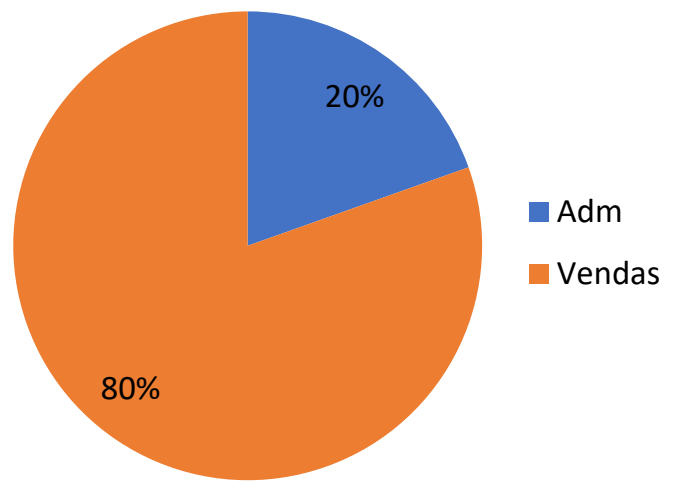

Fonte: Autor.

O Gráfico 5 apresenta uma informação importante para esta pesquisa, que é o tempo de serviço, ou seja, a quantidade de tempo que a pessoa está vinculada à empresa.

Gráfico 5: Análise do Tempo de Serviço.

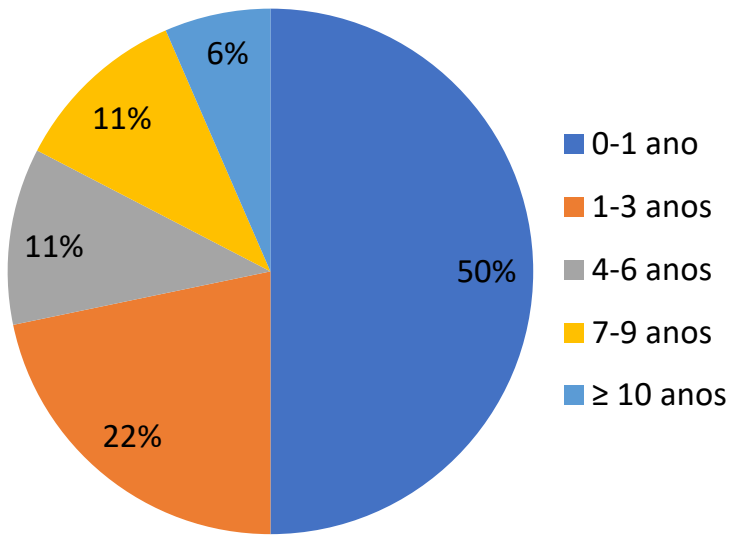

Fonte: Autor

O resultado dessa informação chama atenção pelo fato de que $50 \%$ dos colaboradores apresentam tempo de serviço de até 1 ano. Comparando o Gráfico $5 \mathrm{com}$ o Gráfico 4, dos $50 \%$ com até 1 ano de trabalho, $91 \%$ atua na área de vendas e $9 \%$ no setor administrativo, caracterizando o alto turn-over (rotatividade) no setor de vendas.

Outra informação relevante, demonstrada no Gráfico 6, é o número de colaboradores com dependentes.
Gráfico 6: Número de colaboradores com dependentes.

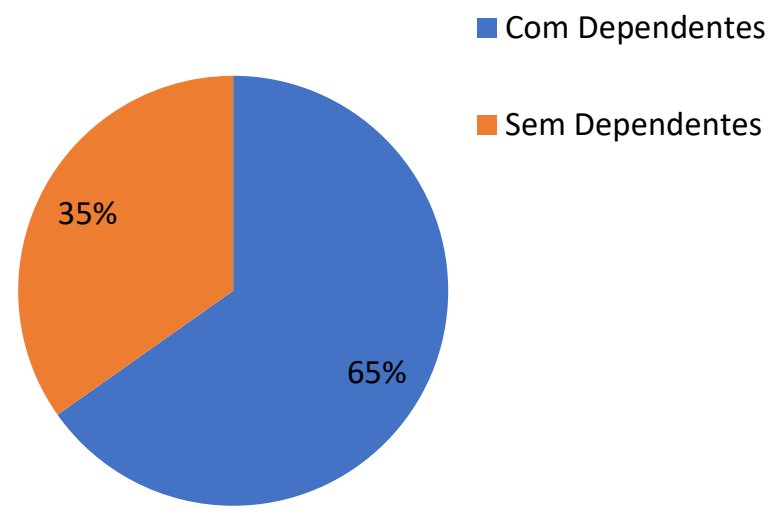

Fonte: Autor.

O resultado do Gráfico 6 mostra que $65 \%$ dos colaboradores possuem dependentes familiares. Comparando esse gráfico com os Gráficos 4 e 5, dos $65 \%$ com dependentes, $56 \%$ atuam na área de vendas e $52 \%$ são do gênero feminino e atuam com vendas.

\subsection{Características Gerais da QVT}

Para definir os fatores críticos de qualidade de vida no trabalho da distribuidora de cosméticos, foi utilizada a média aritmética de cada item que compunha o questionário. O questionário foi composto por 3 colunas, a primeira apresentava o item de avaliação, a segunda apresentava a importância que o colaborador dava ao item, e a terceira o nível de satisfação. A segunda e terceira coluna receberam notas de 1 a 5 , onde o número 1 apresentava o menor valor e o número 5 o valor máximo, conforme a Tabela 2 .

Tabela 2: Níveis de importância e satisfação usados no questionário.

\begin{tabular}{|cccc|}
\hline $\begin{array}{c}\text { IMPORTÂNCIA } \\
\text { ATRIBUÍDA }\end{array}$ & & \multicolumn{2}{c|}{ SATISFAÇÃO ATUAL } \\
\hline Nada importante & $\mathbf{1}$ & Muito insatisfeito & $\mathbf{1}$ \\
\hline Pouco importante & $\mathbf{2}$ & Insatisfeito & $\mathbf{2}$ \\
\hline $\begin{array}{c}\text { Razoavelmente } \\
\text { importante }\end{array}$ & $\mathbf{3}$ & Indiferente & $\mathbf{3}$ \\
\hline Muito importante & $\mathbf{4}$ & Satisfeito & $\mathbf{4}$ \\
\hline $\begin{array}{c}\text { Extremamente } \\
\text { importante }\end{array}$ & $\mathbf{5}$ & Muito satisfeito & $\mathbf{5}$ \\
\hline
\end{tabular}

Fonte: Autor. 
Para estabelecer o nível de satisfação foi criado um ranking que relaciona as médias aritméticas obtidas com os dados da Tabela 1 . Conforme mostradana Tabela 3, foi possível obter 3 fatores críticos, visto que, suas médias ficaram entre 2,89 e 2,98 , sendo classificadas como razoáveis.

Tabela 3: Ranking dos fatores críticos gerais.

\begin{tabular}{ccc|}
\hline $\begin{array}{c}\text { ITENS } \\
\text { AVALIADOS }\end{array}$ & $\begin{array}{c}\text { IMPORTÂNCIA } \\
\text { ATRIBUÍDA }\end{array}$ & $\begin{array}{c}\text { SATISFAÇÃO } \\
\text { ATUAL }\end{array}$ \\
\hline $\mathbf{4}$ & 3,76 & 2,98 \\
$\mathbf{1 9}$ & 3,91 & 2,96 \\
\hline $\mathbf{1 8}$ & 3,43 & 2,89 \\
\hline
\end{tabular}

Fonte: Autor.

No questionário do anexo 1 , o item 18 faz menção às situações e frequência de demissão no ambiente de trabalho, e o item 19 ao incentivo que a empresa dá ao estudo, ambos os itens se encaixam no quarto fator do modelo de Walton: Oportunidade de crescimento e segurança. $O$ item 4 menciona os benefícios extras que a empresa proporciona como alimentação, transporte, médico, dentista, sendo encaixado no primeiro fator do modelo de Walton: Compensação justa e adequada.

Analisando os fatores críticos, tendo como base os dados sociais e conversas com colaboradores, foi possível perceber que o número de colaboradores recém-contratados (com até 1 ano de empresa) justifica a baixa satisfação encontrada no item 18, gerando uma alta insegurança ao colaborador. Além disso, em relação ao item 19 , foi constatado que a empresa não possui vínculo com instituição educativa ou algum programa que promova bolsa de estudo.Com relação ao item 4 , foi constatado que a empresa não oferece plano de saúde e dentário, - que poderia justificar o altoturn-over (rotatividade) em vendas, assim como,a falta de plano de saúde (e/ou dentário) que envolva dependentes, visto que, $56 \%$ dos colaboradores que atuam em vendas possuem dependentes.

Como forma de melhorar os índices de satisfação e garantir uma qualidade de vida no trabalho mais satisfatória, de forma que estimule o potencial humano, a empresa deve acatar os 3 fatores críticos e desenvolver planos de ação para melhoria.

A pesquisa apresentou outros fatores dentro dos 35 itens avaliados, os quais tiveram uma importância elevada, entretanto, esses apresentaram um grau de satisfação classificados entre boa e ótima. A Tabela 4apresenta o ranking dos demais itens e suas médias aritméticas.

Tabela 4: Ranking dos fatores satisfatórios

\begin{tabular}{|c|c|c|}
\hline $\begin{array}{l}\text { NO DO ITEM } \\
\text { AVALIADO }\end{array}$ & $\begin{array}{c}\text { IMPORTÂNCIA } \\
\text { ATRIBUÍDA }\end{array}$ & $\begin{array}{l}\text { SATISFAÇÃO } \\
\text { ATUAL }\end{array}$ \\
\hline 34 & 4,54 & 4,54 \\
\hline 32 & 4,32 & 4,39 \\
\hline 31 & 4,37 & 4,34 \\
\hline 21 & 4,34 & 4,28 \\
\hline 35 & 4,43 & 4,17 \\
\hline 24 & 4,26 & 4,10 \\
\hline 15 & 4,06 & 4,08 \\
\hline 12 & 4,17 & 4,06 \\
\hline 5 & 3,98 & 4,02 \\
\hline 17 & 4,34 & 4,00 \\
\hline 26 & 4,10 & 3,98 \\
\hline 22 & 4,28 & 3,96 \\
\hline 25 & 4,30 & 3,96 \\
\hline 33 & 4,00 & 3,96 \\
\hline 30 & 4,02 & 3,93 \\
\hline 23 & 4,10 & 3,91 \\
\hline 27 & 4,02 & 3,87 \\
\hline 7 & 3,80 & 3,84 \\
\hline 20 & 3,93 & 3,78 \\
\hline 28 & 3,89 & 3,78 \\
\hline 6 & 3,96 & 3,76 \\
\hline 14 & 3,93 & 3,76 \\
\hline 11 & 3,87 & 3,74 \\
\hline 13 & 3,82 & 3,74 \\
\hline 29 & 3,70 & 3,56 \\
\hline 8 & 3,93 & 3,50 \\
\hline 9 & 3,74 & 3,50 \\
\hline 10 & 3,87 & 3,41 \\
\hline 16 & 4,06 & 3,34 \\
\hline 3 & 3,67 & 3,15 \\
\hline 2 & 3,63 & 3,13 \\
\hline 1 & 3,96 & 3,10 \\
\hline
\end{tabular}

Fonte: Autor.

Comparando o ranking da Tabela 4 com a classificação do nível de satisfação da Tabela 1 , os itens $34 ; 32 ; 31 ; 21 ; 35$ e 24 foram classificados como ótimos, sendo os demais classificados como bons.Com relação aos itens classificados como ótimos, foi possível perceber que os colaboradores visualizam a distribuidora como uma empresa que possui serviços e produtos de alta qualidade, tendo uma boa imagem perante a sociedade e uma política de recursos humanos satisfatória, além disso, possui um ambiente onde 0 relacionamento entre gestores e subordinados é harmoniosa e os direitos do trabalhador são respeitados, gerando orgulho na realização do trabalho. 


\section{CONCLUSÃO}

Com este trabalho foi possível conhecera história e os conceitos de qualidade de vida no trabalho, e entender que a percepção de QVT varia de indivíduo para indivíduo. Utilizando o questionário composto por 35 questões, com base no modelo de Walton, foram identificados 3 fatores críticos: situação e frequência de demissão (item 18), incentivo ao estudo (item 19) e benefícios extras (item 4) e seus respectivos níveis de satisfação e importância.

Os dados sociodemográficos mostraram-se importantes quando relacionados aos fatores críticos, para o diagnóstico do motivo de insatisfação dos colaboradores. De um modo geral, a distribuidora não apresentou níveis de satisfação classificados como ruins ou péssimos, apenas os níveis razoável, bom e ótimo. Contudo, o item 18 (situação e frequência de demissões) apresentou a menor média aritmética de satisfação no valor de 2,89 e o item 34 (produtos e serviços oferecidos) apresentou a maior média no valor de 4,54.

Por fim, a QVT é uma ferramenta importante para a gestão de negócio, visto que, auxilia a tomada de decisão com o objetivo de diminuir a insatisfação dos colaboradores e como consequência disso, aumentar a produtividade no trabalho.

\section{REFERÊNCIAS}

[1] SEBRAE. Em Cinco Anos, Número de Pequenos Negócios Crescerá 43\%. Revista Pequenas Empresas e Grandes Negócios, Out.2017. Disponível em:

https://revistapegn.globo.com/Empreendedorism o/noticia/2017/10/em-cinco-anos-numero-depequenos-negocios-crescera-43.html. Acesso em: 28 fev. 2018.

[2] LASCIO, R. H. C. di. Qualidade de vida no trabalho: sentido e significado para empresa e colaborador. In: ROSSI, A. M.; MEURS, J. A.; PERREWÉ, P. L. (org.). Stress e Qualidade de Vida no Trabalho: Melhorando a Saúde e o Bem-estar dos Funcionários. São Paulo: Atlas, 2013. p. 37-54.

[3] CHIAVENATO, I. Administração Geral e Pública: Teoria e mais de $\mathbf{5 0 0}$ questões com gabarito. Rio de Janeiro: Elsevier, 2008.
[4] FERNANDES, E. C. Qualidade de Vida no Trabalho: Como Medir para Melhorar.

Salvador: Casa da Qualidade, 1996.

[5] ANDRADE, R. M. Qualidade de Vida no Trabalho dos Colaboradores da Empresa Farben S/A Indústria Química. Universidade do Extremo Sul Catarinense. Criciúma-SC, 2012.

[6] ANTLOGA, C. S. Práticas Gerenciais e Qualidade de Vida no Trabalho: 0 Caso das Micro e Pequenas Empresas do Setor de Serviços de Alimentação em Brasília. Brasília, 2009.

[7] FREITAS, A. L. P.; SOUZA, R. G. de. Um Modelo para Avaliação da Qualidade de Vida no Trabalho em Universidades Públicas. Revista Eletrônica Sistemas \& Gestão. v. 2. n. 4. p. 136-154, 2009.

[8] GONÇALVES, G. V. de O. Qualidade de Vida no Trabalho: Um Estudo de Caso em Empresa do Setor de Mineração. Faculdades Integradas de Pedro Leopoldo. Pedro LeopoldoMG, 2006 .

[9] ANDRADE, L. A. A. Qualidade de Vida no Trabalho: Um Estudo de Caso no $15^{\circ}$ Batalhão da Polícia Militar na Região Metropolitana de Porto Alegre. Universidade Federal do Rio Grande do Sul. Porto Alegre-RS, 2010.

[10] WALTON, R. E. Improving the quality of work life. Harvard Business Review, Boston, v. 12. n. $155,1973$.

[11] LIMONGI-FRANÇA, A. C. Qualidade de vida no trabalho: conceitos, abordagens, inovaçõese desafios nas empresas brasileiras, Revista Brasileira de Medicina Psicossomática. Rio de Janeiro, v. 1, n. 2, p. 79-83, abr./mai./jun. 1997.

[12] JUNIOR, M. S. P. Qualidade de Vida no Trabalho: Um Estudo com os Docentes e os Servidores Administrativos da Escola Técnica Estadual Professor José Luiz de Mendonça. 2015. Universidade Federal de Pernambuco, Caruaru-PE, 2015.

[13] LIMA, A. C. ; LENZI, G. C. Qualidade de Vida no Trabalho: A Percepção dos Colaboradores de uma Microempresa de Serviços de Florianópolis. 2016. Trabalho de Conclusão de Curso (Graduação em Administração) - Centro Sócio Econômico, 
Universidade Federal de Santa Catarina, Florianópolis - SC, 2016. 


\section{Anexo 1}

AVALIAÇ̃̃o DA QUALIDADE DE VIDA NO TRABALHO SEGUNDO O MODELO DE WALTON

\section{Faixa etária:}

( ) Até 20 anos ( ) 21 a 30 anos

31 a 40 anos ( 41 a 45 anos

46 a 50 anos ( ) Acima de 50 anos

\section{Gênero:}

\section{( ) Feminino}

( ) Masculino

Dependentes:

( ) Não

( ) Sim

\section{Instruções}

Este questionário é sobre como você se sente a respeito da sua Qualidade de Vida no Trabalho, sendo formado por 35 questões que devem ser avaliados sobre duas escalas: importância e satisfação.

Na primeira coluna, corresponde ao grau de importância que você dá a cada item, de acordo com a seguinte escala:

1 - NADA IMPORTANTE

2 - POUCO IMPORTANTE

3 - RAZOAVELMENTE IMPORTANTE

4 - MUITO IMPORTANTE

5 - EXTREMAMENTE IMPORTANTE

Na segunda coluna, corresponde o seu nível de satisfação atual com relação aos itens citados, de acordo com a seguinte escala:

1 - MUITO INSATTSFEITO

2 - INSATISFEITO

3 - NEM INSATISFEITO/NEM SATISFEITO (INDIFERENTE)

4 - SATISFEITO

5 - MUITO SATISFEITO

\section{Escolaridade:}

Ensino Médio ( )Técnioø

() Ensino superior incompleto

( ) Pós-graduação

\section{Area de trabalho:}

( ) Administrativo

\section{( ) Vendas}

\section{Tempo de serviço:}

( ) Até 1 ano ( ) 1-3 anos ( ) 4-6 anos

( ) $7-9 \operatorname{anos}($ ) 10 anos ou mais

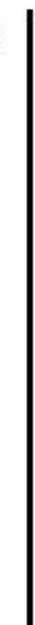

\section{Em relação ao salário (compensação) justo e adequado:}

\begin{tabular}{|c|c|c|c|}
\hline \multicolumn{2}{|c|}{ Item de avaliação } & Importância Atribuida & Satisfação Atual \\
\hline 1 & $\begin{array}{c}\text { O quanto você está satisfeito } \\
\text { com o seu salário? } \\
\text { (remuneração) }\end{array}$ & $(1)-(2)-(3)-(4)-(5)$ & $(1)-(2)-(3)-(4)-(5)$ \\
\hline 2 & $\begin{array}{c}\text { O quanto vocé está satisfeito } \\
\text { com o seu salário, se você } \\
\text { comparar com os salários de } \\
\text { seus colegas? }\end{array}$ & $(1)-(2)-(3)-(4)-(5)$ & $(1)-(2)-(3)-(4)-(5)$ \\
\hline 3 & $\begin{array}{c}\text { O quanto você está satisfeito } \\
\text { com as recompensas e a } \\
\text { participação em resultados que } \\
\text { você recebe da empresa? }\end{array}$ & (1) - (2) - (3) - (4) - (5) & $(1)-(2)-(3)-(4)-(5)$ \\
\hline 4 & $\begin{array}{c}\text { quanto você está satisfeito } \\
\text { com os benefícios extras } \\
\text { (alimentação, transporte, } \\
\text { médico, dentista, etc.) que a } \\
\text { empresa oferece? }\end{array}$ & (1) - (2) - (3) - (4) - (5) & (1) - (2) - (3) - (4) - (5) \\
\hline
\end{tabular}

Em relação as suas condiçóes de trabalho:

\begin{tabular}{|c|c|c|c|}
\hline \multicolumn{2}{|c|}{ Item de avaliação } & Importância Atribuida & Satisfação Atual \\
\hline 5 & $\begin{array}{c}\text { O quanto você está satisfeito } \\
\text { com sua jornada de trabalho } \\
\text { semanal (quantidade de horas } \\
\text { trabalhadas)? }\end{array}$ & $(1)-(2)-(3)-(4)-(5)$ & $(1)-(2)-(3)-(4)-(5)$ \\
\hline 6 & $\begin{array}{c}\text { Em relação a sua carga de } \\
\text { trabalho (quantidade de } \\
\text { trabalho), como voô̂ se sente? }\end{array}$ & $(1)-(2)-(3)-(4)-(5)$ & $(1)-(2)-(3)-(4)-(5)$ \\
\hline 7 & $\begin{array}{c}\text { Em relação ao uso de } \\
\text { tecnologia no trabalho que voô̂ } \\
\text { faz, como você se sente? }\end{array}$ & $(1)-(2)-(3)-(4)-(5)$ & $(1)-(2)-(3)-(4)-(5)$ \\
\hline 8 & $\begin{array}{c}\text { Oquanto vocế está satisfeito } \\
\text { com a sua salubridade } \\
\text { (condições de trabalho) do seu } \\
\text { local de trabalho? }\end{array}$ & $(1)-(2)-(3)-(4)-(5)$ & $(1)-(2)-(3)-(4)-(5)$ \\
\hline 9 & $\begin{array}{c}\text { O quanto você está satisfeito } \\
\text { com os equipamentos de } \\
\text { segurança, proteção individual } \\
\text { e coletiva disponibilizados pela } \\
\text { empresa? }\end{array}$ & (1) - (2) - (3) - (4) - (5) & $(1)-(2)-(3)-(4)-(5)$ \\
\hline 1 & $\begin{array}{c}\text { Em relação ao cansaço que seu } \\
\text { trabalho lhe causa como você } \\
\text { se sente? }\end{array}$ & (1) - (2) - (3) - (4) - (5) & (1) - (2) - (3) - (4) - (5) \\
\hline 0
\end{tabular}


Qualidade de Vida no Trabalho: Um Estudo de Caso em uma Distribuidora de Cosméticos

Em relação ao uso das suas capacidades no trabalho:

\begin{tabular}{|l|c|c|c|}
\hline \multicolumn{2}{|c|}{ Item de avaliação } & Importância Atribuída & Satisfação Atual \\
\hline 1 & $\begin{array}{c}\text { Você está satisfeito com a } \\
\text { autonomia (oportunidade de } \\
\text { tomar decisão) que possui no } \\
\text { seu trabalho? }\end{array}$ & $(1)-(2)-(3)-(4)-(5)$ & $(1)-(2)-(3)-(4)-(5)$ \\
\hline 1 & $\begin{array}{c}\text { Você está satisfeito com a } \\
\text { importância da } \\
\text { tarefa/trabalho/atividade que } \\
\text { você faz? }\end{array}$ & $(1)-(2)-(3)-(4)-(5)$ & $(1)-(2)-(3)-(4)-(5)$ \\
\hline 1 & $\begin{array}{c}\text { Em relação à poli-valência } \\
\text { (possibilidade de realizar várias } \\
\text { tarefas e trabalhos) no } \\
\text { trabalho, como você se sente? }\end{array}$ & (1) - (2) - (3) - (4) - (5) & $(1)-(2)-(3)-(4)-(5)$ \\
\hline 1 & $\begin{array}{c}\text { O quanto você está satisfeito } \\
\text { com sua avaliação de } \\
\text { desempenho (ter conhecimento } \\
\text { de o quanto bom ou ruim está } \\
\text { seu desempenho no trabalho)? }\end{array}$ & (1) - (2) - (3) - (4) - (5) & (1) - (2) - (3) - (4) - (5) \\
\hline 1 & $\begin{array}{c}\text { Em relação a responsabilidade } \\
\text { conferida (responsabilidade de } \\
\text { trabalho dada a você), como } \\
\text { você se sente? }\end{array}$ & (1) - (2) - (3) - (4) - (5) & (1) - (2) - (3) - (4) - (5) \\
\hline
\end{tabular}

Em relação às oportunidades que você tem no seu trabalho:

\begin{tabular}{|l|c|c|c|}
\hline \multicolumn{2}{|c|}{ Item de avaliação } & Importância Atribuída & Satisfação Atual \\
\hline 1 & $\begin{array}{c}\text { O quanto você está satisfeito } \\
\text { com sua oportunidade de } \\
\text { crescimento profissional? }\end{array}$ & $(1)-(2)-(3)-(4)-(5)$ & $(1)-(2)-(3)-(4)-(5)$ \\
\hline 1 & $\begin{array}{c}\text { 0 quanto você está satisfeito } \\
\text { com os treinamentos que você } \\
\text { faz? }\end{array}$ & $(1)-(2)-(3)-(4)-(5)$ & $(1)-(2)-(3)-(4)-(5)$ \\
\hline 1 & $\begin{array}{c}\text { Em relação as situaç̃̃es e a } \\
\text { frequência em que ocorrem as } \\
\text { demissões no seu ambiente de } \\
\text { trabalho, como vocêse sente ? }\end{array}$ & $(1)-(2)-(3)-(4)-(5)$ & $(1)-(2)-(3)-(4)-(5)$ \\
\hline 1 & $\begin{array}{c}\text { Em relação ao incentivo que a } \\
\text { empresa da pra você estudar, } \\
\text { como você se sente? }\end{array}$ & $(1)-(2)-(3)-(4)-(5)$ & $(1)-(2)-(3)-(4)-(5)$ \\
\hline
\end{tabular}

Em relação à integração social no seu trabalho:

\begin{tabular}{|l|c|c|c|}
\hline \multicolumn{2}{|c|}{ Item de avaliação } & Importância Atribuída & Satisfação Atual \\
\hline 2 & $\begin{array}{c}\text { Em relação a discriminação ( } \\
\text { social, racial, religiosa, sexual, } \\
\text { etç) no seu trabalho, como você } \\
\text { se sente? }\end{array}$ & $(1)-(2)-(3)-(4)-(5)$ & $(1)-(2)-(3)-(4)-(5)$ \\
\hline 2 & $\begin{array}{c}\text { Em relação ao seu } \\
\text { relacionamento com colegas e } \\
\text { chefes, como você se sente? }\end{array}$ & $(1)-(2)-(3)-(4)-(5)$ & $(1)-(2)-(3)-(4)-(5)$ \\
\hline 2 & $\begin{array}{c}\text { Em relação ao } \\
\text { comprometimento da sua } \\
\text { equipe e colegas com o } \\
\text { trabalho, como você se sente? }\end{array}$ & $(1)-(2)-(3)-(4)-(5)$ & $(1)-(2)-(3)-(4)-(5)$ \\
\hline 2 & $\begin{array}{c}\text { o quanto você está satisfeito } \\
\text { com a valorização de suas } \\
\text { ideias e iniciativas no trabalho? }\end{array}$ & (1) - (2) - (3) - (4) - (5) & $(1)-(2)-(3)-(4)-(5)$ \\
\hline
\end{tabular}

Em relação ao constitucionalismo (respeito às leis) do seu trabalho:

\begin{tabular}{|l|c|c|c|}
\hline \multicolumn{2}{|c|}{ Item de avaliação } & Importância Atribuída & Satisfação Atual \\
\hline 2 & $\begin{array}{c}\text { o quanto você está satisfeito } \\
\text { com a empresa por ela } \\
\text { respeitar os direitos do } \\
\text { trabalhador? }\end{array}$ & $(1)-(2)-(3)-(4)-(5)$ & $(1)-(2)-(3)-(4)-(5)$ \\
\hline 2 & $\begin{array}{c}\text { O quanto você está satisfeito } \\
\text { com sua liberdade de expressão } \\
\text { (oportunidade de se dar } \\
\text { opinião) no trabalho? }\end{array}$ & $(1)-(2)-(3)-(4)-(5)$ & $(1)-(2)-(3)-(4)-(5)$ \\
\hline 2 & $\begin{array}{c}\text { O quanto você está satisfeito } \\
\text { com as normas e regras do seu } \\
\text { trabalho? }\end{array}$ & $(1)-(2)-(3)-(4)-(5)$ & $(1)-(2)-(3)-(4)-(5)$ \\
\hline 2 & $\begin{array}{c}\text { Em relação ao respeito à sua } \\
\text { individualidade (características } \\
\text { individuais e particularidades) } \\
\text { no trabalho, como você se } \\
\text { sente? }\end{array}$ & (1) - (2) - (3) - (4) - (5) & (1) - (2) - (3) - (4) - (5) \\
\hline
\end{tabular}


Revista de Engenharia e Pesquisa Aplicada, v. 4, n. 4, p. 60 -72, 2019

Em relação ao espaço que o trabalho ocupa na sua vida:

\begin{tabular}{|c|c|c|c|}
\hline \multicolumn{2}{|r|}{ Item de avaliação } & Importância Atribuída & Satisfação Atual \\
\hline $\begin{array}{l}2 \\
8\end{array}$ & $\begin{array}{l}\text { O quanto você está satisfeito } \\
\text { com a influência do trabalho } \\
\text { sobre sua vida/rotina familiar? }\end{array}$ & $(1)-(2)-(3)-(4)-(5)$ & $(1)-(2)-(3)-(4)-(5)$ \\
\hline $\begin{array}{l}2 \\
9\end{array}$ & $\begin{array}{c}\text { O quanto você está satisfeito } \\
\text { com a influência no trabalho } \\
\text { sobre sua possibilidade de } \\
\text { lazer? }\end{array}$ & $(1)-(2)-(3)-(4)-(5)$ & $(1)-(2)-(3)-(4)-(5)$ \\
\hline $\begin{array}{l}3 \\
0\end{array}$ & $\begin{array}{c}\text { O quanto você está satisfeito } \\
\text { com seus horários de trabalho e } \\
\text { descanso? }\end{array}$ & $(1)-(2)-(3)-(4)-(5)$ & $(1)-(2)-(3)-(4)-(5)$ \\
\hline
\end{tabular}

\section{Em relação à relevância social e importância do seu trabalho:}

\begin{tabular}{|c|c|c|c|}
\hline \multicolumn{2}{|r|}{ Item de avaliação } & Importância Atribuída & Satisfação Atual \\
\hline $\begin{array}{l}3 \\
1\end{array}$ & $\begin{array}{c}\text { Em relação ao orgulho de } \\
\text { realizar o seu trabalho, como } \\
\text { você se sente? }\end{array}$ & $(1)-(2)-(3)-(4)-(5)$ & $(1)-(2)-(3)-(4)-(5)$ \\
\hline $\begin{array}{l}3 \\
2\end{array}$ & $\begin{array}{c}\text { Você está satisfeito com a } \\
\text { imagem que esta empresa tem } \\
\text { perante a sociedade? }\end{array}$ & $(1)-(2)-(3)-(4)-(5)$ & $(1)-(2)-(3)-(4)-(5)$ \\
\hline $\begin{array}{l}3 \\
3\end{array}$ & $\begin{array}{c}\text { O quanto vocé está satisfeito } \\
\text { com a integração comunitária ( } \\
\text { contribuição com a sociedade) } \\
\text { que a empresa tem? }\end{array}$ & $(1)-(2)-(3)-(4)-(5)$ & $(1)-(2)-(3)-(4)-(5)$ \\
\hline $\begin{array}{l}3 \\
4\end{array}$ & $\begin{array}{c}\text { O quanto você está satisfeito } \\
\text { com os serviços prestados e a } \\
\text { qualidade dos produtos que a } \\
\text { empresa fabrica? }\end{array}$ & $(1)-(2)-(3)-(4)-(5)$ & $(1)-(2)-(3)-(4)-(5)$ \\
\hline $\begin{array}{l}3 \\
5\end{array}$ & $\begin{array}{c}\text { O quanto você está satisfeito } \\
\text { com a política de recursos } \\
\text { humanos ( a forma de a } \\
\text { empresa tratar os funcionários) } \\
\text { que a empresa tem? }\end{array}$ & $(1)-(2)-(3)-(4)-(5)$ & $(1)-(2)-(3)-(4)-(5)$ \\
\hline
\end{tabular}

OBRIGADO PELA COLABORAÇÃO!!! 